\title{
Second-trimester abortion attitudes and practices among maternal-fetal medicine and family planning subspecialists
}

\author{
J. L. Kerns ${ }^{1 *} \mathbb{D}$, J. K. Turk' , C. M. Corbetta-Rastelli², M. G. Rosenstein ${ }^{1,2}$, A. B. Caughey ${ }^{3}$ and J. E. Steinauer ${ }^{1}$
}

\begin{abstract}
Background: Patients deciding to undergo dilation and evacuation (D\&E) or induction abortion for fetal anomalies or complications may be greatly influenced by the counseling they receive. We sought to compare maternal-fetal medicine (MFM) and family planning (FP) physicians' attitudes and practice patterns around second-trimester abortion for abnormal pregnancies.

Methods: We surveyed members of the Society for Maternal-Fetal Medicine and Family Planning subspecialists in 2010-2011 regarding provider recommendations between D\&E or induction termination for various case scenarios. We assessed provider beliefs about patient preferences and method safety regarding D\&E or induction for various indications. We compared responses by specialty using descriptive statistics and conducted unadjusted and adjusted analyses of factors associated with recommending a D\&E.

Results: Seven hundred ninety-four (35\%) physicians completed the survey (689 MFMs, 105 FPs). We found that FPs had 3.9 to 5.5 times higher odds of recommending D\&E for all case scenarios (e.g. 80\% of FPs and $41 \%$ of MFMs recommended D\&E for trisomy 21). MFMs with exposure to family planning had greater odds of recommending D\&E for all case scenarios ( $p<0.01$ for all). MFMs were less likely than FPs to believe that patients prefer D\&E and less likely to feel that D\&E was a safer method for different indications.

Conclusion: Recommendations for D\&E or induction vary significantly depending on the type of physician providing the counseling. The decision to undergo D\&E or induction is one of clinical equipoise, and physicians should provide unbiased counseling. Further work is needed to understand optimal approaches to shared decision making for this clinical decision.
\end{abstract}

Keywords: Abortion, Dilation and evacuation, Family planning, Induction termination, Maternal fetal medicine, Provider attitudes

\section{Background}

Women deciding to terminate a pregnancy in the second trimester for fetal anomalies or pregnancy complications can undergo one of two procedures - either a dilation and evacuation (D\&E), or an induction termination. D\&Es are faster, and most are done in the outpatient setting with sedation, while induction terminations typically are done on labor and delivery units, require more time, and offer more contact with the fetus [1].

\footnotetext{
*Correspondence: jennifer.kerns@ucsf.edu

'Department of Obstetrics, Gynecology and Reproductive Sciences,

University of California, 1001 Potrero Avenue, Ward 6D, San Francisco, CA

94110, USA

Full list of author information is available at the end of the article
}

Although D\&E and induction termination are both safe and effective [2], the decision to undergo D\&E or induction is not always driven by choice. Access to both methods varies across the United States (US) with state, local, and institutional restrictions, insurance concerns, and provider availability posing barriers, most of which disproportionately affect D\&E access. Only half of all $\mathrm{Ob} /$ Gyn residency programs offer training in D\&E [3]; fellowship training in family planning (FP) always includes D\&E training, and about one-third of maternalfetal medicine (MFM) fellowships include D\&E training [4]. Beyond training, access to D\&E abortions remains quite limited across the US [5]. Despite these barriers,

(C) The Author(s). 2020 Open Access This article is distributed under the terms of the Creative Commons Attribution 4.0 International License (http://creativecommons.org/licenses/by/4.0/), which permits unrestricted use, distribution, and 
$\mathrm{D} \& \mathrm{E}$ is the most common method of second-trimester abortion [6] and women seeking abortion for fetal anomalies are still more likely to undergo D\&E [7].

Studies have shown that provider opinion and preference affect health-related communication and clinical decisions $[8,9]$ and can be a barrier to high-quality care [10]. Because abortion skills are taught differentially according to subspecialty and geographic area of the US, there is good reason to believe that $\mathrm{Ob} / \mathrm{Gyn}$ physicians, and specifically those who counsel women seeking second-trimester abortion, have different preferences for methods of second-trimester abortion - that is, D\&E or induction termination.

Women value the ability to choose their method of abortion [11] but are not always offered both methods [7]. Women deciding between D\&E or induction termination frequently interact with either MFM or FP physicians, and the counseling they receive may differ based on physician subspecialty. We sought to compare MFM and FP physicians' attitudes and practices around second-trimester abortion for abnormal pregnancies. The findings from our study will inform any future strategies to improve patient-centered and unbiased counseling for patients deciding between D\&E and induction termination.

\section{Methods}

We conducted an anonymous survey in 2010-2011 of all US members of the Society for Maternal-Fetal Medicine (SMFM) and FP subspecialists, defined as all faculty and fellows associated with the Family Planning Fellowship (FFP). SMFM provided names and postal addresses for SMFM members. We obtained names and email addresses of current and former FP fellows from the national FFP office. In addition, the directors at each fellowship site provided the names and emails of FP faculty. We obtained email addresses for some MFMs from publicly available information, such as publications on PubMed or institutional websites. We invited all subjects for whom we had an email address to complete an online survey using Key Survey. In accordance with human subjects approval, participants' informed consent was provided by participants launching the survey. Several analyses have been published from the parent survey on D\&E and inductions practices among family planning and maternal-fetal medicine subspecialists $[4,12,13]$.

The survey probed respondents for their beliefs about patient preferences and their understanding of safety regarding D\&E or induction for various indications, as well as their recommendations between D\&E or induction termination for different case scenarios. In order to understand their opinions about patient preference and method safety, we presented five indications for termination: undesired pregnancy, fetal anomaly, severe maternal morbidity, abortion between 14 and 19 weeks, and abortion between 20 and 24 weeks. We asked physicians which method (D\&E or induction or no preference) patients generally prefer for the above indications and which method physicians thought was safer (D\&E or induction or no difference in safety). We also presented case scenarios for a patient requesting abortion at 20 weeks' gestation for six different reasons: trisomy 21 , renal agenesis, intrauterine fetal demise (IUFD), severe pre-eclampsia, chorioamnionitis with sepsis, and preterm premature rupture of membranes (PPROM). We asked physicians which method they would recommend for each scenario (recommend D\&E, recommend D\&E but patient's choice, no recommendation, recommend induction but patient's choice, or recommend induction). We asked physicians which method is most commonly done at their institution for these scenarios.

We collected demographic information, practice characteristics, training in and provision of second-trimester abortion and institutional regulations and barriers to offering second-trimester abortion services. To ensure anonymity, respondents were only asked to identify the region of the US and population size of the city where they practice. We assessed intrinsic religious motivation [14] using three validated questions with true or false responses; scores ranged from 0 to 3 with higher scores reflecting greater intrinsic religious motivation [14]. We assessed abortion attitudes using a validated scale with five questions on a five-point Likert scale [15]. Scores ranged from 5 to 25 , with higher scores reflecting more favorable abortion attitudes. We defined FP exposure as presence of an FP fellowship at a past or current institution.

We compared MFM and FP attitudes towards, and recommendations for, D\&E or induction termination. We used descriptive statistics to compare responses by specialty for indications and case scenarios. We analyzed the recommendation responses as "any recommendation", "patient choice", or "no recommendation". We conducted unadjusted and adjusted analyses of factors associated with recommending a D\&E for each case scenario. For the adjusted analysis, we dichotomized responses into D\&E recommendation ("recommend $D \& E$ " and "recommend D\&E, but patient's choice") versus induction or no recommendation ("no recommendation", "recommend induction" and "recommend induction, but patient's choice"). We also did an adjusted analysis of factors associated with MFM recommendations for D\&E. We determined a priori to include age, gender, practice setting, religious and abortion attitudes, and providing D\&Es as covariates. Exposure to an FP fellowship (past or current) was only included in the analysis with MFM physicians. We offered respondents a $\$ 5$ gift card that was not contingent upon starting or completing the survey. We performed all analyses using Stata 12 (StataCorp 2011, 
College Station, TX). The University of California, San Francisco Committee on Human Research approved this study.

\section{Results}

Of the 2294 subjects (2125 MFMs, 169 FPs) who received an email or paper survey invitation, 794 (35\%) responded (689 MFMs, 105 FPs). Most participants were women under 50 years of age. Most worked in an academic setting (71\%) and were fellowship trained (98\%). About one in five MFM respondents had exposure to a FP fellowship (Table 1).

Recommendations for D\&E were more common than actual D\&E provision at respondents' institutions. Among all respondents (MFMs and FPs combined), D\&E was recommended with the following frequency: $47 \%$ for trisomy $21,42 \%$ for renal agenesis, $35 \%$ for IUFD, $49 \%$ for severe pre-eclampsia, $46 \%$ for chorioamnionitis with sepsis, and 26\% for PPROM. D\&E was the most common method done at their institution with the following frequency: $49 \%$ for trisomy $21 ; 37 \%$ for renal agenesis; $24 \%$ for IUFD; $26 \%$ for severe pre-eclampsia; $29 \%$ for chorioamnionitis with sepsis; $14 \%$ for PPROM.

When presented with six case scenarios and asked about how they would counsel women for D\&E or induction, MFMs were roughly twice as likely to make any recommendation (either for D\&E or induction) compared to FPs for the following scenarios (10\% vs $5 \%$ trisomy $21 ; 15 \%$ vs $7 \%$ renal agenesis; $18 \%$ vs $10 \%$ IUFD; $22 \%$ vs $7 \%$ PPROM) (Table 2). For cases of maternal disease, MFMs and FPs were approximately as likely to make a recommendation ( $32 \%$ vs $28 \%$ severe preeclampsia; $49 \%$ vs $55 \%$ chorioamnionitis with sepsis). For all scenarios other than chorioamnionitis, MFMs were less likely than FPs to state that recommendations should be driven by patient choice ( $54 \%$ vs $76 \%$ trisomy $21 ; 57 \%$ vs $72 \%$ renal agenesis; $58 \%$ vs $60 \%$ IUFD; $49 \%$ vs $61 \%$ severe pre-eclampsia; $45 \%$ vs $63 \%$ PPROM).

MFMs were less likely than FPs to believe that patients prefer D\&E (Fig. 1) for undesired pregnancies, fetal anomalies, maternal morbidity, abortions between 14 and 19 weeks and abortions between 20 and 24 weeks ( $p \leq 0.02$ for all). MFMs were less likely than FPs to feel that D\&E was a safer method (compared to induction or neither) for all of the same indications listed above (Fig. 2) ( $p<0.01$ for all).

In unadjusted analyses, there was a statistically significant difference between MFM and FP recommendations for all case scenarios (Table 3). When asked whether they would recommend D\&E for a patient requesting termination at 20 weeks' gestation for specific scenarios, MFMs were less likely than FPs to recommend D\&E for

Table 1 Characteristics of maternal-fetal medicine (MFM) and family planning (FP) subspecialists who responded to the survey

\begin{tabular}{|c|c|c|c|}
\hline Characteristic & $\begin{array}{l}\text { Total } \\
\text { N (\%) }\end{array}$ & $\begin{array}{l}\text { MFM } \\
\text { n (\%) }\end{array}$ & $\begin{array}{l}\text { FP } \\
\text { n (\%) }\end{array}$ \\
\hline Total & 794 & $689(87)$ & $105(13)$ \\
\hline \multicolumn{4}{|l|}{ Demographics } \\
\hline Age, years ${ }^{a, b}$ & & $47 \pm 10$ & $39 \pm 8$ \\
\hline Female $^{b}$ & 442 & $352(51)$ & $90(86)$ \\
\hline West region ${ }^{b}$ & 206 & $174(25)$ & $32(30)$ \\
\hline Northeast region ${ }^{\mathrm{b}}$ & 257 & $222(32)$ & $35(33)$ \\
\hline South/Southeast region ${ }^{b}$ & 168 & $158(23)$ & $10(10)$ \\
\hline Midwest region ${ }^{\mathrm{b}}$ & 157 & $130(19)$ & $27(26)$ \\
\hline Home city population $<1$ million ${ }^{b}$ & 446 & $394(57)$ & $52(50)$ \\
\hline \multicolumn{4}{|l|}{ Clinical Practice } \\
\hline Supervises trainees (fellows, residents) & 700 & $599(87)$ & $101(96)$ \\
\hline Works $>50 \%$ time in academic setting ${ }^{b}$ & 563 & $470(68)$ & $93(89)$ \\
\hline Fellowship trained & 775 & $685(99)$ & $90(86)$ \\
\hline Family planning fellowship at current institution ${ }^{b}$ & 229 & $143(21)$ & $86(82)$ \\
\hline Family planning fellowship at previous institution ${ }^{b}$ & 181 & $150(22)$ & $31(30)$ \\
\hline Provide D\&Es & 324 & $224(33)$ & $100(95)$ \\
\hline \multicolumn{4}{|l|}{ Personal Beliefs } \\
\hline Intrinsic religious motivation ${ }^{\mathrm{a}, \mathrm{b}}$ & & $2.3 \pm 0.9$ & $2.6 \pm 0.7$ \\
\hline Abortion attitudes ${ }^{a, b}$ & & $17 \pm 4$ & $22 \pm 3$ \\
\hline
\end{tabular}

${ }^{\mathrm{a}}$ mean $\pm \mathrm{SD}$, not $\mathrm{n}(\%)$

${ }^{b}$ missing data 
Table 2 Proportion of maternal-fetal medicine (MFM) and family planning (FP) subspecialists who gave a recommendation for D\&E or induction only, a recommendation for D\&E or induction but patient's choice, or gave no recommendation for each case scenario

\begin{tabular}{|c|c|c|c|}
\hline & Total & $\begin{array}{l}\text { MFM } \\
\text { N (\%) }\end{array}$ & $\begin{array}{l}\text { FP } \\
N(\%)\end{array}$ \\
\hline TOTAL & & 689 & 105 \\
\hline
\end{tabular}

Trisomy 21

Recommendation (D\&E or induction)
D\&E
Induction
Patient choice (D\&E or induction)
D\&E
Induction

No recommendation

Renal agenesis

Recommendation (D\&E or induction)

D\&E

Induction

Patient choice (D\&E or induction)

D\&E

Induction

No recommendation

Intrauterine fetal demise

Recommendation (D\&E or induction)
D\&E
Induction
Patient choice (D\&E or induction)
D\&E
Induction

No recommendation

Severe pre-eclampsia

$\begin{array}{llll}\text { Recommendation (D\&E or induction) } & 252 & 223(32) & 29(28) \\ \quad \text { D\&E } & 148 & 119(17) & 29(28) \\ \quad \text { Induction } & 104 & 104(15) & 0(0) \\ \text { Patient choice (D\&E or induction) } & 403 & 339(49) & 64(61) \\ \quad \text { D\&E } & 242 & 180(26) & 62(59) \\ \quad \text { Induction } & 161 & 159(23) & 2(2) \\ \text { No recommendation } & 135 & 123(18) & 12(11) \\ \text { Chorioamnionitis with sepsis } & & & \\ \text { Recommendation (D\&E or induction) } & 398 & 340(49) & 58(55) \\ \quad \text { D\&E } & 207 & 153(22) & 54(51) \\ \quad \text { Induction } & 191 & 187(27) & 4(4) \\ \text { Patient choice (D\&E or induction) } & 313 & 275(40) & 38(36) \\ \quad \text { D\&E } & 156 & 122(18) & 34(32) \\ \text { Induction } & 157 & 153(22) & 4(4)\end{array}$

Table 2 Proportion of maternal-fetal medicine (MFM) and family planning (FP) subspecialists who gave a recommendation for D\&E or induction only, a recommendation for D\&E or induction but patient's choice, or gave no recommendation for each case scenario (Continued)

\begin{tabular}{llll}
\hline & Total & $\begin{array}{l}\text { MFM } \\
\text { N (\%) }\end{array}$ & FP (\%) \\
\hline No recommendation & 80 & $71(10)$ & $9(9)$ \\
Preterm premature rupture of membranes & & & \\
Recommendation (D\&E or induction) & 161 & $154(22)$ & $7(7)$ \\
D\&E & 45 & $38(6)$ & $7(7)$ \\
Induction & 116 & $116(17)$ & $0(0)$ \\
Patient choice (D\&E or induction) & 379 & $313(45)$ & $66(63)$ \\
$\quad$ D\&E & 161 & $99(14)$ & $62(59)$ \\
Induction & 218 & $214(31)$ & $4(4)$ \\
No recommendation & 250 & $219(32)$ & $31(30)$ \\
\hline
\end{tabular}

trisomy 21 (41\% vs 80\%, respectively); renal agenesis ( $37 \%$ vs $78 \%$, respectively); IUFD ( $30 \%$ vs $72 \%$, respectively); severe pre-eclampsia ( $44 \%$ vs $87 \%$, respectively); chorioamnionitis with sepsis ( $40 \%$ vs $84 \%$, respectively); PPROM ( $20 \%$ vs $66 \%$, respectively) ( $p<0.001$ for all).

In our adjusted analyses of FPs and MFMs (Table 3), we found that FPs had 3.9 to 5.5 times higher odds of recommending D\&E for all case scenarios. Higher physician age was significantly associated with a D\&E recommendation for trisomy 21, renal agenesis, IUFD, and PPROM ( $p \leq 0.05$ for all). Greater religiosity was significantly associated with a D\&E recommendation for trisomy 21 , renal agenesis, IUFD and PPROM ( $p \leq 0.05$ for all). Working in a non-academic setting was associated with lower odds of recommending D\&E for chorioamnionitis $(p=0.001)$ and providing D\&Es was associated with higher odds of recommending D\&E for chorioamnionitis $(p=0.01)$. A more favorable abortion attitude and being a FP provider were independent predictors of recommending D\&E for all case scenarios $(p<0.01$ for all).

In our adjusted analyses of MFMs only, we found that MFMs with exposure to family planning had greater odds of recommending D\&E for all case scenarios compared to MFMs without exposure to family planning (Table 4). Higher physician age was significantly associated with a D\&E recommendation for trisomy 21, renal agenesis, IUFD, and PPROM. Greater religiosity was significantly associated with a D\&E recommendation for renal agenesis, IUFD, chorioamnionitis, and PPROM. More favorable abortion attitudes were significantly associated with a D\&E recommendation for all case scenarios, except IUFD. Providing D\&Es increased the odds of recommending D\&E for chorioamnionitis. Additionally, we found lower odds of recommending $D \& E$ for chorioamnionitis by physicians working in a non-academic setting. 


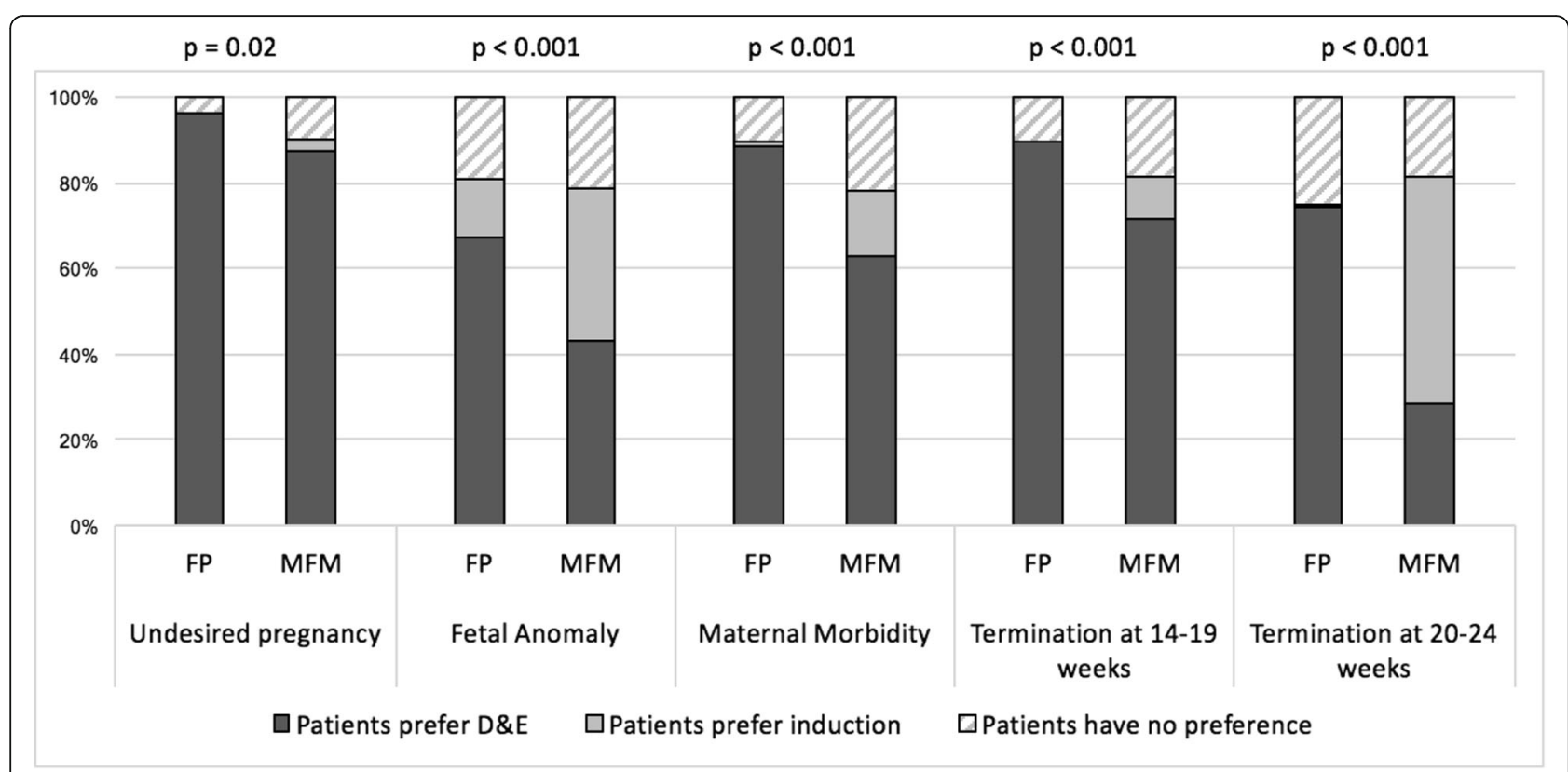

Fig. 1 Proportions of FP and MFM physicians who believe patients prefer D\&E, induction, or have no preference for different indications

\section{Discussion}

In this study we investigated MFM and FP physicians' attitudes and practices around second-trimester abortions for abnormal pregnancies. MFMs were less likely than FPs to believe that patients prefer D\&E and to make a recommendation for D\&E for all case scenarios. MFMs with exposure to family planning were more likely to recommend D\&E compared to MFMs without exposure.
Our findings are consistent with other studies showing that physicians' biases affect recommendations for treatments around pregnancy termination. In one survey of MFM physicians, counseling around management of life-threatening fetal anomalies differed according to physician demographics, with younger physicians and those in academic practice more likely to offer a choice of either induction or D\&E [16]. One study of MFMs found that physicians' negative attitudes towards late

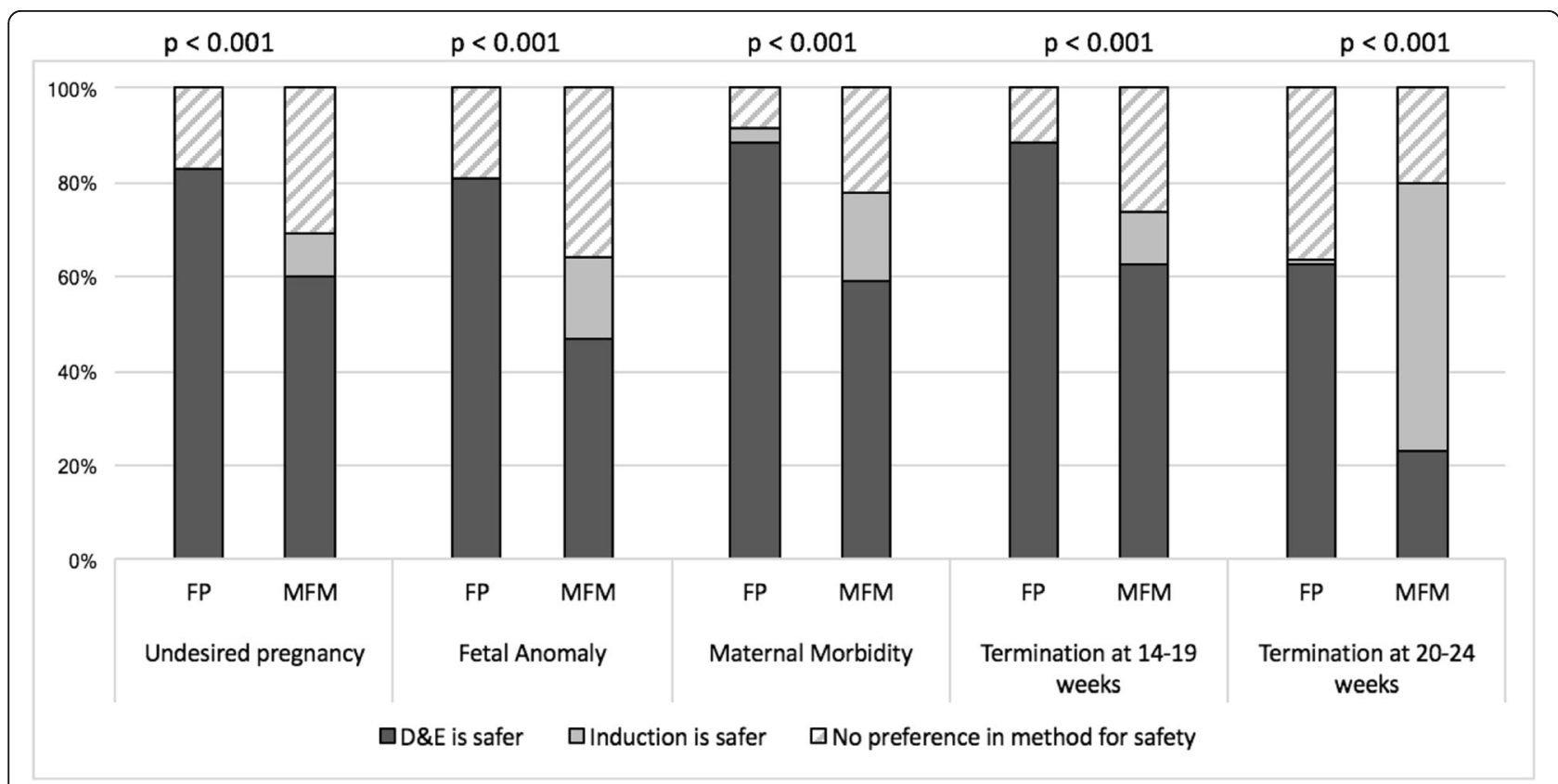

Fig. 2 Proportions of FP and MFM physicians who believe D\&E is safer, induction is safer, or no difference in safety for different indications 
Table 3 Unadjusted and adjusted odds of a family planning (FP) versus maternal-fetal medicine (MFM) physician recommending D\&E for each case scenario

\begin{tabular}{|c|c|c|c|c|}
\hline Case scenario & $\begin{array}{l}\text { FP } \\
\text { n (\%) }\end{array}$ & $\begin{array}{l}\text { MFM } \\
n(\%)\end{array}$ & $\begin{array}{l}\text { Unadjusted } \\
\text { OR ( } 95 \% \text { Cl) }\end{array}$ & $\begin{array}{l}\text { Adjusted }^{a} \\
\text { OR }(95 \% \text { Cl) }\end{array}$ \\
\hline \multicolumn{5}{|l|}{ Trisomy 21} \\
\hline Induction recommendation or no recommendation ${ }^{b}$ & $21(20)$ & $401(59)$ & - & - \\
\hline D\&E recommendation ${ }^{c}$ & $84(80)$ & $284(41)$ & $5.7(3.4-9.3)$ & $3.9(2.1-7.0)$ \\
\hline \multicolumn{5}{|l|}{ Renal agenesis } \\
\hline Induction recommendation or no recommendation & $23(22)$ & $435(63)$ & - & - \\
\hline D\&E recommendation & $82(78)$ & $251(37)$ & $6.2(3.8-10.1)$ & $4.3(2.4-7.6)$ \\
\hline \multicolumn{5}{|l|}{ Intrauterine fetal demise } \\
\hline Induction recommendation or no recommendation & $29(28)$ & $480(70)$ & - & - \\
\hline D\&E recommendation & $76(72)$ & $203(30)$ & $6.2(3.9-9.8)$ & $4.2(2.4-7.3)$ \\
\hline \multicolumn{5}{|l|}{ Severe pre-eclampsia } \\
\hline Induction recommendation or no recommendation & $14(13)$ & $386(56)$ & - & - \\
\hline D\&E recommendation & $91(87)$ & $299(44)$ & $8.4(4.7-15.0)$ & $4.6(2.4-8.8)$ \\
\hline \multicolumn{5}{|l|}{ Chorioamnionitis with sepsis } \\
\hline Induction recommendation or no recommendation & $17(16)$ & $411(60)$ & - & - \\
\hline D\&E recommendation & $88(84)$ & $275(40)$ & $7.7(4.5-13.3)$ & $4.2(2.2-7.8)$ \\
\hline \multicolumn{5}{|l|}{ Preterm premature rupture of membranes } \\
\hline Induction recommendation or no recommendation & $35(34)$ & $549(80)$ & - & - \\
\hline D\&E recommendation & $69(66)$ & $137(20)$ & $7.9(5.0-12.4)$ & $5.5(3.1-9.7)$ \\
\hline
\end{tabular}

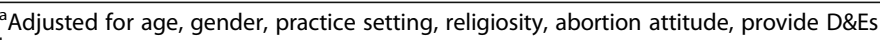

b Induction recommendation or no recommendation includes responses "no recommendation", "recommend induction", and "recommend induction, but patient's choice"

"D\&E recommendation includes responses "recommend D\&E" and "recommend D\&E, but patient's choice"

abortion and physicians practicing outside of the Western region were associated with a lower likelihood of discussing termination as an option [17]. We found religiosity to be associated with physicians' recommendations for D\&E or induction, a finding consistent with a study demonstrating that religious primary care physicians give less weight to a patient's expressed wishes and values when making an ethically complex medical decision [18]. Counseling recommendations that patients receive for second-trimester abortion can vary widely based on the individual physician.

We found striking differences around physicians' beliefs and attitudes about safety for both methods (D\&E versus induction), with MFMs more likely than FPs to believe that D\&E is less safe than induction across all queried indications. With respect to major complications, such as hemorrhage, infection or additional major surgery, D\&E is at least as safe, if not safer, than induction termination $[2,19]$. The American College of Obstetricians and Gynecologists advises physicians to offer patients a choice between methods given that there is clinical equipoise with regard to the safety of each procedure [19]. And research demonstrates that patients highly value having a choice [7, 11]; however, our findings indicate that there is a significant difference between MFM and FP physicians' beliefs about what method patients prefer. This likely reflects a cultural difference between MFMs and FPs, and our respondents' beliefs about patient preferences may, in fact, have more to do with their preferences rather than patient preferences. Physicians who wish to authentically engage in shared decision making and support patients in valuesdriven decisions for abortion might consider reflective tools [20] to help clarify the effects of their personal beliefs on recommendations around D\&E or induction.

We observed that MFM physicians with exposure to family planning (either current or past) were more likely to recommend D\&E than MFMs without exposure. We know that training in abortion provision increases residents' intention to provide abortion services after residency [21], with even partial participation being associated with increased acceptance of abortion [22]. Increasing exposure to abortion care and training also improves trainees' experiences and skill sets. Threequarters of MFM fellows believe that D\&E training should be included during fellowship [12]; however, many MFMs will encounter barriers to providing abortions [13]. By strengthening collaborations between FP and MFM fellowships, we can provide more training opportunities for MFM fellows. In addition, building viable 
Table 4 Association of family planning (FP) exposure, past or current, with D\&E recommendation by maternal-fetal medicine (MFM) physicians for each case scenario

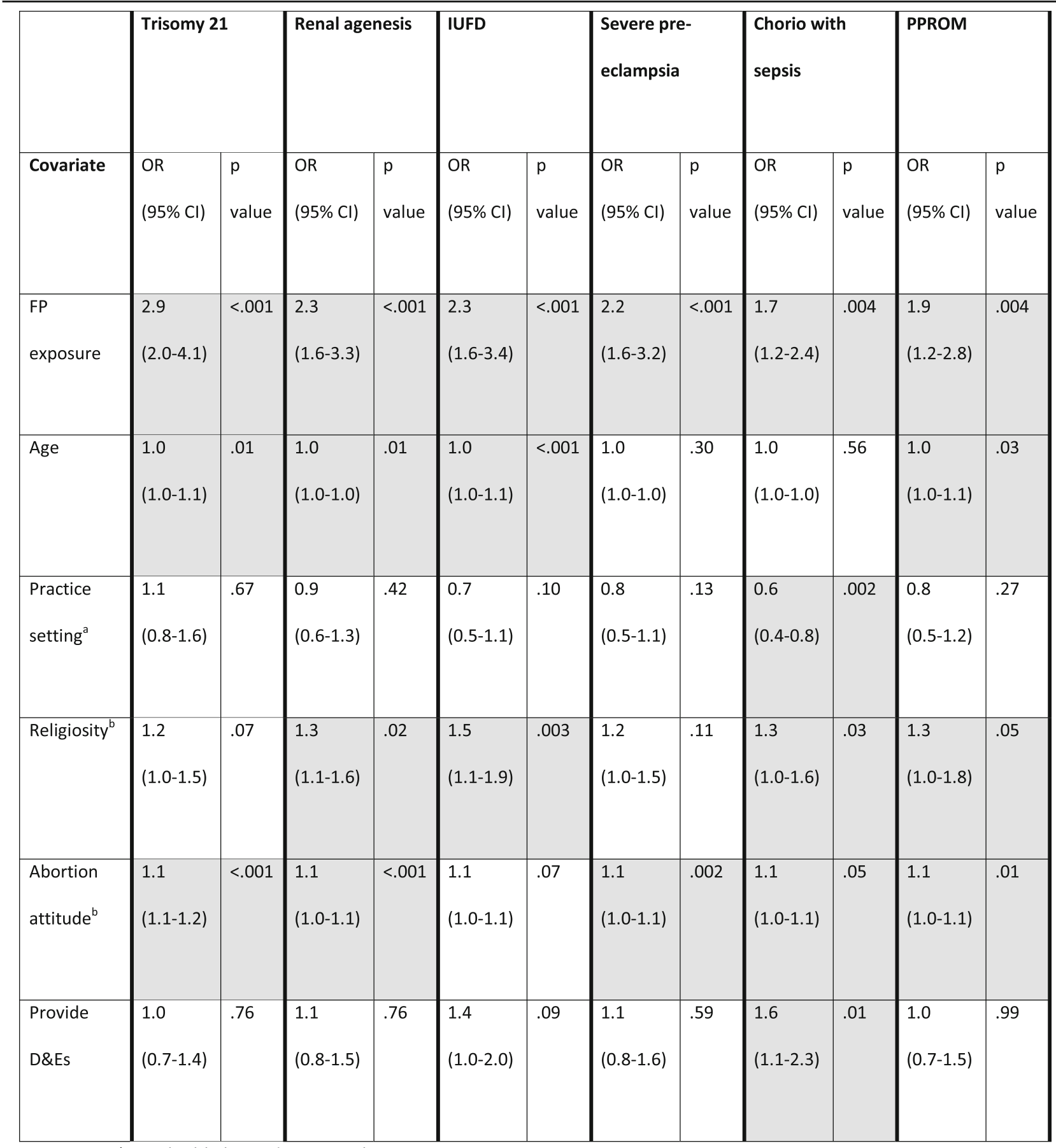

*gray highlights indicate $\mathrm{p}$ value $\leq 0.05$

${ }^{a}$ higher proportion indicates non-academic setting

${ }^{b}$ higher score indicates greater religiosity and more favorable abortion attitudes 
relationships with nearby FP fellowships or clinics can improve referral networks and patient-centered care.

Given the variety of recommendations patients receive around pregnancy termination, a standardized approach should be taken to adequately inform and equip women regarding their options. Shared-decision making is a counseling strategy that is effective in increasing decisions consistent with patients' values [23, 24]. By engaging in shared-decision making and standardizing recommendations around pregnancy termination, patients will receive more comprehensive and personalized care around this sensitive decision.

Increasing collaboration and strengthening referral networks between MFM and FP programs may provide both subspecialists with improved expertise and counseling strategies around second-trimester abortions for abnormal pregnancies. Health policy makers have repeatedly called for implementation of interdisciplinary collaboration as a key approach to improve the quality and safety of patient care [25]. The use of interprofessional activities with an external facilitator or interprofessional meetings were found to improve adherence to recommended practices [26]. By creating opportunities for MFM and FP subspecialists to work together, patients will receive more inclusive clinical care.

There are limitations to our study. First, as a crosssectional study, we are only able to determine associations but not causality. Second, although our response rate is comparable to previous surveys [16, 17], it is unclear whether our sample is representative of all MFM and FP physicians. We also recognize that there are many reasons why physicians may recommend a D\&E or induction, most notably logistical barriers to D\&E. While we did not assess reasons for a D\&E or induction recommendation with each case scenario, we did assess physicians' beliefs about the relative safety and patient preferences for each method as a way to contextualize the responses to the case scenarios.

\section{Conclusions}

MFM and FP physicians commonly counsel patients around method of abortion procedure in the setting of fetal anomalies or pregnancy complications, and their biases likely affect the recommendation that patients receive. Counseling around D\&E or induction should be approached from a shared decision-making framework. Such an approach would minimize provider bias, maximize a values-based decision, and improve patient-centered care.

\section{Abbreviations}

D\&E: Dilation and evacuation; FP: Family planning; MFM: Maternal-fetal medicine

\section{Acknowledgments}

Not applicable.

\section{Authors' contributions}

JK was responsible for study conception and design, acquisition of study data, analysis and interpretation of the data, and manuscript preparation. JT was responsible for analysis of the data. CCR was responsible for manuscript preparation. MR was responsible for revision of the manuscript. AC was responsible for revision of the manuscript. JS was responsible for revision of the manuscript. All authors read and approved the final manuscript.

\section{Funding}

Not applicable.

\section{Availability of data and materials}

The datasets used and/or analyzed during the current study are available from the corresponding author on reasonable request.

Ethics approval and consent to participate

All study providers consented to participate by checking a box next to the phrase "I consent to participate in this study" within the online survey. The University of California San Francisco Committee on Human Research (\#1003559) approved the study. The committee approved the use of the abovementioned consenting process (online check-box).

\section{Consent for publication}

Not applicable.

\section{Competing interests}

The authors declare that they have no competing interests.

\section{Author details}

'Department of Obstetrics, Gynecology and Reproductive Sciences, University of California, 1001 Potrero Avenue, Ward 6D, San Francisco, CA 94110, USA. ${ }^{2}$ Department of Obstetrics, Gynecology and Reproductive Sciences, University of California, 550 16th Street, San Francisco, CA 94158, USA. ${ }^{3}$ Department of Obstetrics and Gynecology of Oregon Health \& Science University, 3181 SW Sam Jackson Park Rd, Portland, OR 97239, USA.

Received: 23 January 2019 Accepted: 24 January 2020

\section{References}

1. Hammond C. Recent advances in second-trimester abortion: an evidencebased review. Am J Obstet Gynecol. 2009:200:347-56.

2. Lohr PA, Hayes JL, Gemzell-Danielsson K. Surgical versus medical methods for second trimester induced abortion. Cochrane Database Syst Rev. 2008; (1):1-20. Art. No.:CD006714. https://doi.org/10.1002/14651858.CD006714. pub2

3. Steinauer JE, Turk JK, Pomerantz T, Simonson K, Leaman LA, Landy U. Abortion Training in U.S. Obstetrics and Gynecology Residency programs. Am J Obstet Gynecol. 2018;108:303.

4. Kerns JL, Steinauer JE, Rosenstein MG, Turk JK, Caughey AB, D'Alton M. Maternal-fetal medicine subspecialists' provision of second-trimester termination services. Am J Perinatol. 2012;29:709-16.

5. Jones RK, Jerman J. Abortion incidence and service availability in the United States, 2011. Perspect Sex Reprod Health. 2014;46:3-14.

6. Jatlaoui TC. Abortion surveillance - United States, 2014. MMWR Surveill Summ. 2017;66(24);1-48.

7. Kerns JL, Mengesha B, McNamara B, Cassidy A, Pearlson G, Kuppermann M. Effect of counseling quality on anxiety, grief, and coping after secondtrimester abortion for pregnancy complications. Contraception. 2018;97(6): $520-23$

8. van Ryn M, Burke J. The effect of patient race and socio-economic status on physicians' perceptions of patients. Soc Sci Med. 2000;50:813-28.

9. van Ryn M. Research on the provider contribution to race/ethnicity disparities in medical care. Med Care. 2002:40(1):-1-140-I-151.

10. Ha JF, Longnecker N. Doctor-patient communication: a review. Ochsner J. 2010;10:38-43

11. Kerns J, Vanjani R, Freedman L, Meckstroth K, Drey EA, Steinauer J. Women's decision making regarding choice of second trimester termination method for pregnancy complications. Int J Gynaecol Obstet. 2012;116:244-8. 
12. Rosenstein MG, Turk JK, Caughey AB, Steinauer JE, Kerns JL. Dilation and evacuation training in maternal-fetal medicine fellowships. Am J Obstet Gynecol. 2014;210:569.e1-5.

13. Kerns JL, Lederle LI, Rosenstein MG, Turk JK, Caughey AB, Steinauer JE. Barriers to dilation and evacuation practice among maternal-fetal medicine subspecialists: quantitative and qualitative results from a national survey. Clin Obstet Gynecol. 2016;2:7.

14. Hoge R. A validated intrinsic religious motivation scale. I Sci Study Relig. 1972;11:369-76

15. Aiyer AN, Ruiz G, Steinman A, Ho GY. Influence of physician attitudes on willingness to perform abortion. Obstet Gynecol. 1999;93:576-80.

16. Heuser CC, Eller AG, Byrne JL. Survey of physicians' approach to severe fetal anomalies. J Med Ethics. 2012;38:391-5.

17. Jacobs AR, Dean G, Wasenda EJ, Porsch LM, Moshier EL, Luthy DA, et al. Late termination of pregnancy for lethal fetal anomalies: a national survey of maternal-fetal medicine specialists. Contraception. 2015;91:12-8.

18. Lawrence RE, Curlin FA. Autonomy, religion and clinical decisions: findings from a national physician survey. J Med Ethics. 2009;35:214-8.

19. No PB. 135: second-trimester abortion. Obstet Gynecol. 2013;121:1394-406.

20. Duggan A, Vicini A, Allen L, Shaughnessy A. Learning to see beneath the surface: a qualitative analysis of family medicine residents' reflections about communication. J Health Commun. 2015;20:1441-8.

21. Steinauer JE, Turk JK, Fulton MC, Simonson KH, Landy U. The benefits of family planning training: a 10-year review of the Ryan residency training program. Contraception. 2013;88:275-80.

22. Steinauer JE, Turk JK, Preskill F, Devaskar S, Freedman L, Landy U. Impact of partial participation in integrated family planning training on medical knowledge, patient communication and professionalism. Contraception. 2014;89:278-85.

23. Edmonds BT. Shared decision-making and decision support: their role in obstetrics and gynecology. Curr Opin Obstet Gynecol. 2014;26:523-30.

24. Barry MJ, Edgman-Levitan S. Shared decision making - the pinnacle of patient-centered care. N Engl J Med. 2012;366:780-1.

25. WHO. | Framework for Action on Interprofessional Education \& Collaborative Practice (WHO/HRH/HPN/10.3). Geneva: WHO; 2017.

26. Reeves S, Pelone F, Harrison R, Goldman J, Zwarenstein M. Interprofessional collaboration to improve professional practice and healthcare outcomes. Cochrane Database Syst Rev. 2017;(6):1-38. Art. No.:CD000072. https://doi. org/10.1002/14651858.CD000072.pub3.

\section{Publisher's Note}

Springer Nature remains neutral with regard to jurisdictional claims in published maps and institutional affiliations.

Ready to submit your research? Choose BMC and benefit from:

- fast, convenient online submission

- thorough peer review by experienced researchers in your field

- rapid publication on acceptance

- support for research data, including large and complex data types

- gold Open Access which fosters wider collaboration and increased citations

- maximum visibility for your research: over $100 \mathrm{M}$ website views per year

At BMC, research is always in progress.

Learn more biomedcentral.com/submissions 